\title{
APLIKASI MONITORING KEUANGAN BAGIAN OPERASIONAL DI STARINDO BERBASIS WEB
}

\author{
Budi Setiadi \\ Teknik Informatika, Fakultas Teknologi Informasi, Universitas Islam Kalimantan Muhammad Arsyad Al-Banjari \\ Jl. Adhyaksa, Jl. Kayu Tangi 1 Jalur 2 No.2, Sungai Miai, Kec. Banjarmasin Utara, Kota Banjarmasin, \\ Kalimantan Selatan 70123 \\ Email : budibtc75@yahoo.com
}

\begin{abstract}
Abstrak- Pengelolaan data keuangan yang diguakan untuk kegiatan operasional dengan mengetikkannya kedalam software Microsoft Office Excel pada perusahaan kurang efisien, sehingga masih rentan terhadap error. Dalam penelitian ini dibuat aplikasi monitoring pengelolaan data keuangan berbasis web untuk menunjang kegiatan operasional yang dijalankan pada PT Starindo. Pembuatan aplikasi ini menggunakan metode waterfall sebagai metode pengembangan perangkat lunak dengan model pendekatan sistem pemrograman terstruktur, bahasa pemograman PHP, dibantu dengan jQuery dan MySQL sebagai server database serta Sublime Text Editor sebagai tools pemrograman. Hasil yang didapat dari pembuatan aplikasi keuangan pada bagian operasional ini adalah petugas kasir mampu menangani permasalahan yang disebabkan oleh kurang efisiennya proses yang ada, mempermudah kinerja petugas kasir dan semua pelaksana kegiatan operasional, serta proses pencatatan, penyimpanan, dan pencarian data keuangan yang digunakan untuk kegiatan operasional menjadi lebih cepat dan akurat.
\end{abstract}

Kata kunci: Web, PHP, MySQL, Aplikasi Keuangan,

\section{PENDAhuluan}

$P$ ada saat ini pengolahan data uang yang digunakan untuk kegiatan operasional di PT. STARINDO masih menggunakan software Microsoft Office Excel, yaitu dengan cara petugas kasir mengetikkan data-data uang yang digunakan untuk kegiatan operasional ke dalamnya, sedangkan untuk membuat laporan dilakukan dengan cara menyalin format yang ada dengan fungsi copy dan paste, ketika laporan sudah dicetak, petugas kasir menyerahkan hasilnya kepada manajer keuangan. Jika prosedur yang digunakan seperti ini, maka manajer keuangan kesulitan untuk memonitor kondisi uang yang digunakan selama kegiatan operasional berlangsung, karena proses pengolahan datanya dilakukan oleh petugas kasir, sedangkan manajer keuangan menerima laporannya jika meminta kepada petugas kasir atau diserahkan oleh petugas kasir. Padahal manajer keuangan memerlukan informasi yang berkaitan dengan kondisi uang yang digunakan untuk kegiatan operasional seperti berapa sisa uang yang tersisa, apakah ada uang yang masuk, atau apakah ada pengguna yang mengajukan bon gantung, atau apakah ada selisih antara stok uang fisik dengan saldo akhir dari data uang yang digunakan selama kegiatan operasional berlangsung, tanpa harus meminta atau menunggu laporannya dari petugas kasir.

Sama halnya pada saat petugas kasir membuat bukti uang kegiatan operasional yang diserahkan ke pengguna uang, menggunakan fungsi copy dan paste format bukti yang ada, tentu cara ini kurang efisien, karena setiap bukti yang dibuat terdapat nomor bukti nya, yang tidak bisa otomatis terupdate apabila membuatnya dengan fungsi copy dan paste. Disi lain, pengguna uang kegiatan operasional tidak dapat melihat data uang yang ia gunakan untuk kegiatan operasional, bisa saja bukti yang ia terima itu hilang.

Dengan semakin bertambahnya data uang kegiatan operasional yang diolah di dalam software Microsoft Office Excel, maka untuk mencari data penggunaannya pun menjadi kurang efisien jika menggunakan fungsi ctrl $+f$ pada software Microsoft Office Excel.

Kebutuhan akan sebuah aplikasi yang mampu memudahkan pengelolaan data uang untuk kegiatan operasional, seperti data kas masuk, data uang muka, data biaya, data bon gantung, data stok uang kas sangat diperlukan. Agar data uang yang digunakan untuk kegiatan operasional dapat diolah menjadi informasi berupa laporan yang tepat dan mudah diperoleh.

Dengan latar belakang yang telah disebutkan, maka penelitian ini dilakukan untuk merancang dan membuat sebuah aplikasi keuangan pada bagian operasional berbasis web.

\section{METODE PENELITIAN}

1. Wawancara

Wawancara digunakan untuk mengetahui hal-hal dari responden secara mendalam. Teknik wawancara yang digunakan adalah wawancara tidak terstruktur (unstructured interview).

2. Observasi

Observasi dilakukan dengan menganalisa kebutuhan yang diperlukan oleh petugas kasir jika prosedur yang ada nantinya di buat sebuah aplikasi.

3. Studi Dokumen

Studi dokumen dilakukan dengan cara mengkaji berbagai dokumen yang dianggap mendukung untuk melengkapi data yang dibutuhkan selama proses perancangan aplikasi ini.

\section{HASIL DAN PEMBAHASAN}

Setelah sistem dianalisis dan didesain maka akan menuju tahap implementasi. Implementasi merupakan tahap meletakan sistem sehingga siap diproses dan bertujuan untuk mengkonfirmasi modul-modul perancangan, sehingga pengguna dapat memberi masukan kepada pengembangan sistem. Dalam mendesain sebuah sistem diperlukan beberapa kompunen antara lain :

\section{Analisis system berjalan}

Berikut adalah contoh dari bagan alir dokumen (document flowchart) suatu prosedur pembuatan laporan kas operasional dengan bantuan software Microsoft Office Excel. 


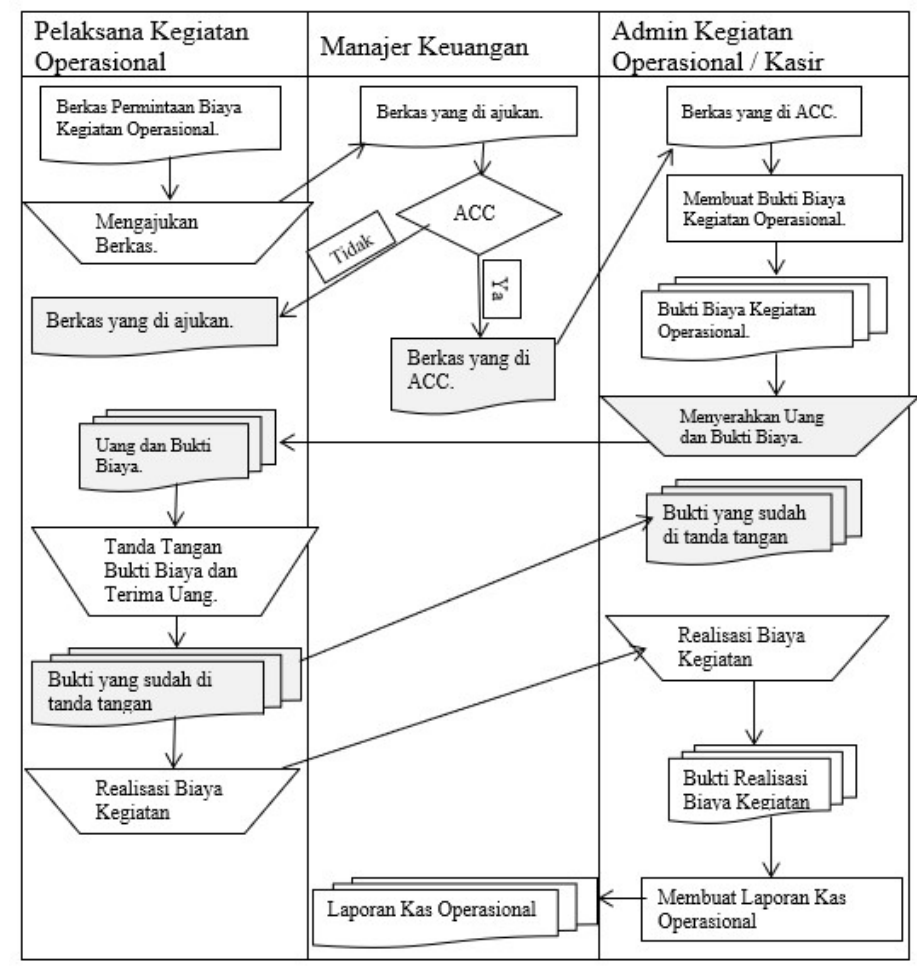

Gambar 1. Diagram Alir Dokumen Prosedur yang Sedang Berjalan

\section{Diagram Konteks}

Diagram Konteks adalah lingkup suatu sistem, yaitu keterkaitan sistem dengan lingkungan. Lingkup ini ditentukan dari besarnya pengaruh data yang diterima dan informasi yang dihasilkan, lingkungan ini diwakili oleh entitas-entitas luar, dimana digambarkan tentang entitas yang memberikan sesuatu kepada atau dari sistem.

Diagram konteks yang digunakan untuk membuat Aplikasi Monitoring Keuangan pada Bagian Operasional di PT STARINDO ialah seperti gambar dibawah ini :

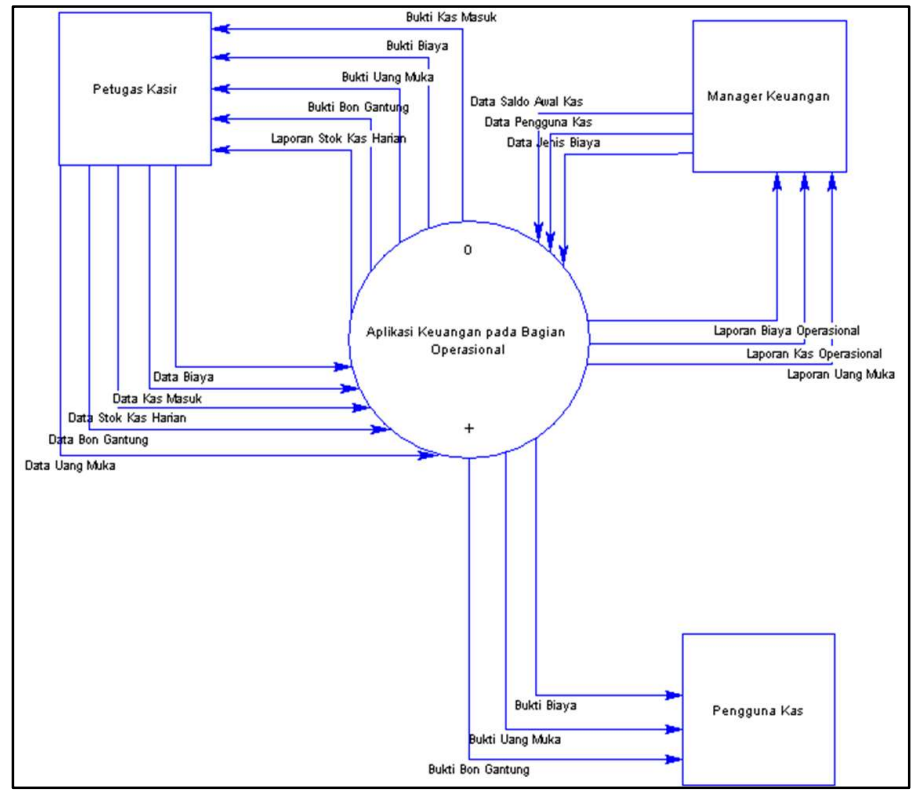

Gambar 2. Rancangan Diagram Konteks

Keterangan :

1. Manager keuangan melakukan input data saldo awal kas, data pengguna kas, dan data jenis biaya agar petugas kasir dapat melakukan input data keuangan yang digunakan untuk kegiatan operasional. Manager keuangan dapat mencetak laporan biaya operasional, laporan kas operasional dan laporan uang muka. 
2. Petugas kasir dapat melakukan input data biaya, data kas masuk, data uang muka, data stok kas harian, dan data bon gantung. Petugas kasir dapat menerima laporan stok kas harian, bukti bon gantung, bukti uang muka, bukti kas masuk dan bukti biaya.

3. Pengguna kas dapat menerima bukti biaya, bukti uang muka, dan bukti bon gantung yang diperoleh dari petugas kasir saat mengelola data keuangan yang digunakan untuk kegiatan operasional.

\section{Relasi antar tabel}

Untuk melihat bagaimana saling terkaitnya antara satu tabel dengan yang lainnya dalam satu database, maka di buat lah sebuah gambaran relasi antar tabel. Adapun relasi antar tabel yang dirancang ialah sebagai berikut :

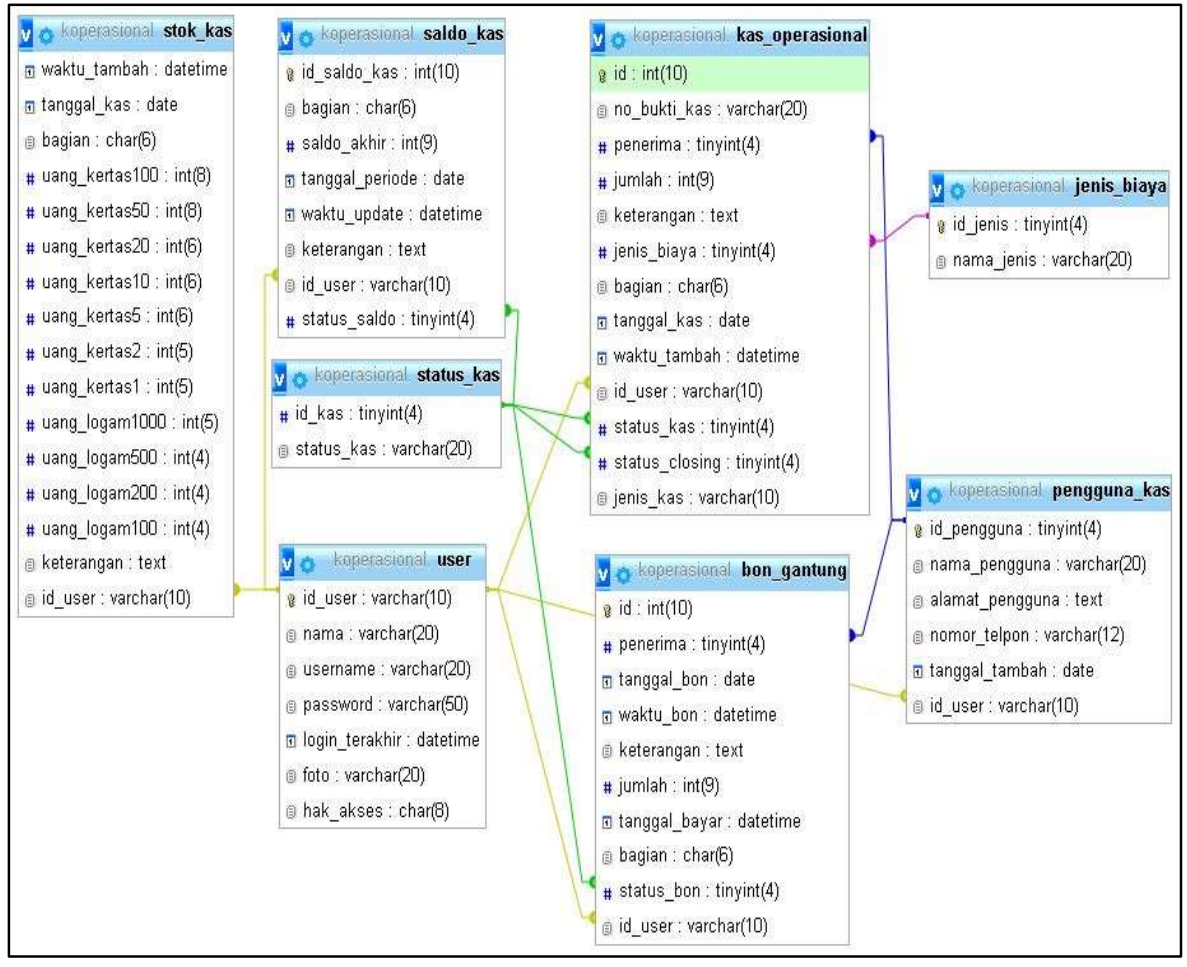

Gambar 3. Relasi Antar Tabel

\section{Tampilan Aplikasi}

Tampilan dari aplikasi digunakan oleh user untuk berinteraksi dengan aplikasi. Desain sistem yang telah dibuat berdasarkan analisis kebutuhan kemudian diimplementasikan ke dalam bahasa pemograman, sehingga semua fungsi dapat dijalankan dengan baik oleh pengguna. Berikut adalah tampilan dari aplikasi yang telah dibuat.

\section{a. Tampilan Halaman Login}

Tampilan ini digunakan oleh user untuk melakukan proses login ke dalam aplikasi agar dapat menggunakan aplikasi yang telah dirancang. Berikut adalah tampilan dari form login.

.:. Halaman Login :..

Aplikasi Keuangan pada Bagian Operasional.

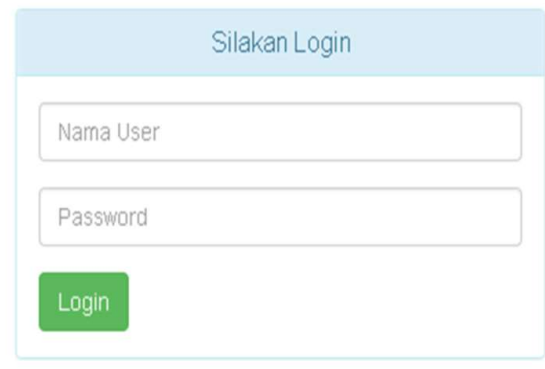

Gambar 4. Tampilan Halaman Login 


\section{b. Tampilan Halaman Utama / Dashboard}

Setelah user berhasil melakukan proses login, maka selanjutnya akan di arahkan ke halaman utama / dashboard. Berikut adalah tampilan dari halaman dashboard yang telah berhasil dibuat.

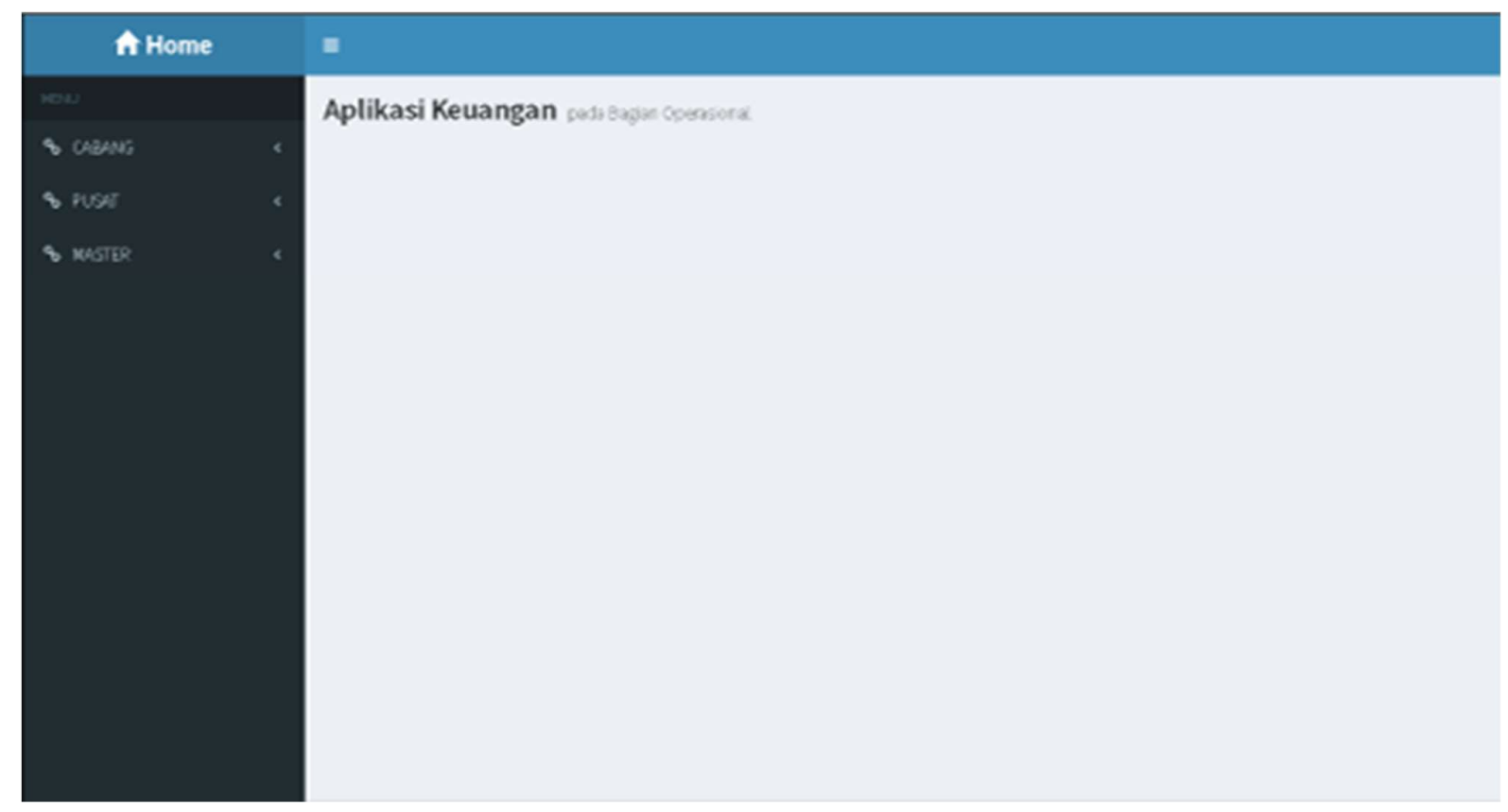

Gambar 5. Tampilan Halaman Dashboard

\section{c. Tampilan Halaman Kas Operasional Pusat}

Halaman ini digunakan untuk menampilkan transaksi kas operasional yang terjadi pada hari yang terpilih, dan juga apabila ingin mencetak laporan kas operasional untuk bagian pusat atau cabang, berikut tampilannya.

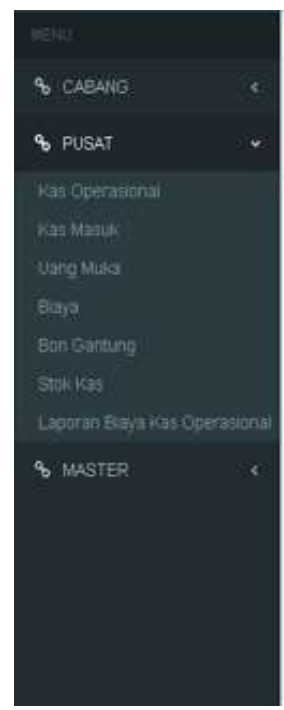

$\therefore$ Kas Operasional Pusat :..

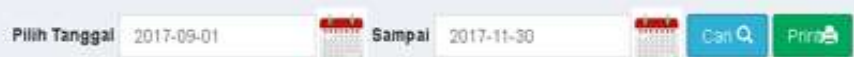

Kas Keluar Beum Closing Kas Masuk Belum Closing :-Ini hondsi pertana tanggal sebetim : 2017-08-31-5also awal 10029250

Saldo awal tanggal 01-September-2017

Fip
Tanggal No. Bukti Kas
2017-11-05 Domanpst axt-2017?
2017-11-06 DO2MNPST N 2017
2017-10-24 DO1/WPST nN:2017

Saldo Axhir 30-November-2017

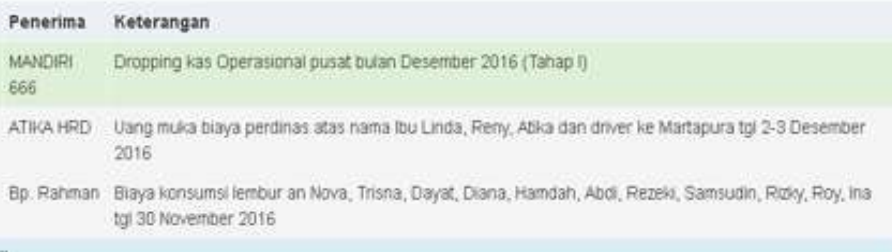
tgi 30 Noventier 2016
10.029 .250 .00

Jumiah

Rp 4358500,00

Fp 300000,00

Ap 165000.00

Rp $13.922 .750,00$

Gambar 6. Tampilan Halaman Kas Operasional Bagian Pusat

\section{d. Tampilan Laporan Biaya Kas Operasional}

Laporan ini digunakan untuk melihat data biaya kas operasional yang digunakan berdasarkan jenis biaya.
Berikut tampilan dari laporan biaya kas operasional yang telah berhasil dibuat. 


\begin{tabular}{|c|c|c|c|c|c|c|c|c|c|c|c|c|c|}
\hline \multicolumn{5}{|c|}{ ST RINDO } & \multirow{2}{*}{\multicolumn{7}{|c|}{ LAPORAN BIAYA KAS OPERASIONAL PUSAT }} & \multirow[b]{2}{*}{ BULAN : } & \multirow[b]{2}{*}{ AGUSTUS } \\
\hline \multirow[b]{2}{*}{ Tg] } & \multirow[b]{2}{*}{ Kantor } & \multirow[b]{2}{*}{ Bonus } & \multirow[b]{2}{*}{ Gaji / Lembur } & \multirow[b]{2}{*}{ Dinas } & & & & & & & & & \\
\hline & & & & & BBM & PLN & PDAM & Intemet & Telpon & Entertain & Hutang & Budget Operasional & Jumlah Biaya \\
\hline 1 & 0 & 0 & 0 & 0 & 0 & 0 & 0 & 0 & 0 & 0 & 0 & 0 & 0 \\
\hline 2 & 0 & 0 & 0 & 0 & 0 & 0 & 0 & 0 & 0 & 0 & 0 & 0 & 0 \\
\hline 3 & 0 & 0 & 0 & 0 & 0 & 0 & 0 & 0 & 0 & 0 & 0 & 0 & 0 \\
\hline 4 & 0 & 0 & 0 & 0 & 0 & 0 & 0 & 0 & 0 & 0 & 0 & 0 & 0 \\
\hline 5 & 0 & 0 & 0 & 0 & 0 & 0 & 0 & 0 & 0 & 0 & 0 & 0 & 0 \\
\hline 6 & 0 & 0 & 0 & 0 & 0 & 0 & 0 & 0 & 0 & 0 & 0 & 0 & 0 \\
\hline$?$ & 0 & 0 & 0 & 0 & 0 & 0 & 0 & 0 & 0 & 0 & 0 & 0 & 0 \\
\hline 8 & 0 & 0 & 0 & 0 & 0 & 0 & 0 & 0 & 0 & 0 & 0 & 0 & 0 \\
\hline 9 & 598000 & 0 & 385000 & 920000 & 200000 & 0 & 0 & 0 & 0 & 375000 & 0 & 343213 & $\mathrm{Eq} 2.821 .21390$ \\
\hline 10 & 0 & 0 & 0 & 0 & 0 & 0 & 0 & 0 & 0 & 0 & 0 & 0 & 0 \\
\hline 11 & 99500 & 0 & 45000 & 60000 & 0 & 0 & 0 & 0 & 0 & 2500000 & 0 & 780000 & $\mathrm{Eq} 3.484 .500 \emptyset 0$ \\
\hline 12 & 0 & 0 & 0 & 0 & 0 & 0 & 0 & 0 & 0 & 0 & 0 & 0 & 0 \\
\hline 13 & 0 & 0 & 0 & 0 & 0 & 0 & 0 & 0 & 0 & 0 & 0 & 0 & 0 \\
\hline 14 & 0 & 0 & 0 & 0 & 0 & 0 & 0 & 0 & 0 & 0 & 0 & 0 & 0 \\
\hline 15 & 0 & 0 & 0 & 0 & 0 & 0 & 0 & 0 & 0 & 0 & 0 & 0 & 0 \\
\hline 16 & 57000 & 0 & 45000 & 270000 & 0 & 0 & 0 & 0 & 0 & 1005400 & 0 & 654500 & Ep 2.031 .90000 \\
\hline 17 & 0 & 0 & 0 & 0 & 0 & 0 & 0 & 0 & 0 & 0 & 0 & 0 & 0 \\
\hline 18 & 0 & 0 & 0 & 0 & 0 & 0 & 0 & 0 & 0 & 0 & 0 & 0 & 0 \\
\hline 19 & 0 & 0 & 0 & 0 & 0 & 0 & 0 & 0 & 0 & 0 & 0 & 0 & 0 \\
\hline 20 & 0 & 0 & 0 & 0 & 0 & 0 & 0 & 0 & 0 & 0 & 0 & 0 & 0 \\
\hline 21 & 0 & 0 & 0 & 0 & 0 & 0 & 0 & 0 & 0 & 0 & 0 & 0 & 0 \\
\hline 22 & 0 & 0 & 0 & 0 & 0 & 0 & 0 & 0 & 0 & 0 & 0 & 0 & 0 \\
\hline 23 & 0 & 0 & 0 & 0 & 0 & 0 & 0 & 0 & 0 & 0 & 0 & 0 & 0 \\
\hline 24 & 0 & 0 & 0 & 0 & 0 & 0 & 0 & 0 & 0 & 0 & 0 & 0 & 0 \\
\hline 25 & 0 & 0 & 0 & 0 & 0 & 0 & 0 & 0 & 0 & 0 & 0 & 0 & 0 \\
\hline 26 & 0 & 0 & 0 & 0 & 0 & 0 & 0 & 0 & 0 & 0 & 0 & 0 & 0 \\
\hline 27 & 0 & 0 & 0 & 0 & 0 & 0 & 0 & 0 & 0 & 0 & 0 & 0 & 0 \\
\hline 28 & 0 & 0 & 0 & 0 & 0 & 0 & 0 & 0 & 0 & 0 & 0 & 0 & 0 \\
\hline 29 & 0 & 0 & 0 & 0 & 0 & 0 & 0 & 0 & 0 & 0 & 0 & 0 & 0 \\
\hline 30 & 0 & 0 & 0 & 0 & 0 & 0 & 0 & 0 & 0 & 0 & 0 & 0 & 0 \\
\hline 31 & 0 & 0 & 0 & 0 & 0 & 0 & 0 & 0 & 0 & 0 & 0 & 0 & 0 \\
\hline & & & & & & & & & & & & TO TAL & Fq $8337.613,00$ \\
\hline
\end{tabular}

Gambar 7. Tampilan Laporan Biaya Kas Operasional

e. Tampilan Laporan Kas Operasional

Berikut adalah tampilan dari laporan kas operasional yang telah berhasil dibuat, yang berisi data kas masuk dan data kas keluar di tanggal yang dipilih. Tampilan laporan kas ini terdiri dari No. Bukti Kas, Penerima, Keterangan, Jumlah, Debet, Kredit dan Saldo.

\section{ST RIN RINO}

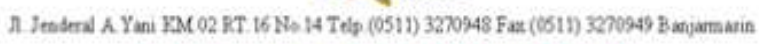

LAPORAN KAS OPERASIONAL PUSAT

\begin{tabular}{|c|c|c|c|c|c|c|}
\hline No Bultika & Penerima & Keterangan & Jumlahi & Debet & Kredit & Saldo \\
\hline \multicolumn{4}{|c|}{ Saldo Awal } & Rp $7.455 .750,00$ & & Rp 7.455,750,00 \\
\hline $\begin{array}{l}\text { 003/Radestivitai } \\
7\end{array}$ & yandi & $\begin{array}{l}\text { Pengembalian UM penbeli an cakndge penter canon untuk BP } \\
\text { Ruamin (ni UM tanggal 2017-0n-20) }\end{array}$ & Ip $490,000,00$ & Fp 400000,00 & & \\
\hline 015/KKPSTNU:2017 & yandi & peeblelina catridge pnites cance untik Bp. Rahmin & Bp 378000,00 & & R.p 378000,00 & \\
\hline 016/KKRSTNR22017 & yoesh HRD & 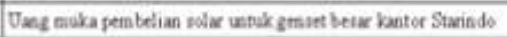 & $8 p 900,000,00$ & & $R_{0} 9900000,00$ & \\
\hline \multicolumn{4}{|c|}{ Total } & Ip 7.855 .750 .00 & Rp $1.388 .000,00$ & Rp $6517,750,00$ \\
\hline \multicolumn{4}{|c|}{ Saldo Akhif } & Rp 65517730,00 & & \\
\hline
\end{tabular}

Gambar 8. Tampilan Laporan Kas Operasional 


\section{f. Tampilan Laporan Stok Kas Harian}

Berikut adalah tampilan dari laporan stok kas harian yang berisi data fisik uang kertas dan uang logam. dari gambar di bawah ini di ketahui nilai uang kertas, uang logam, total uang fisik dan bon gantung serta selisih kurang atau lebih secara detail.

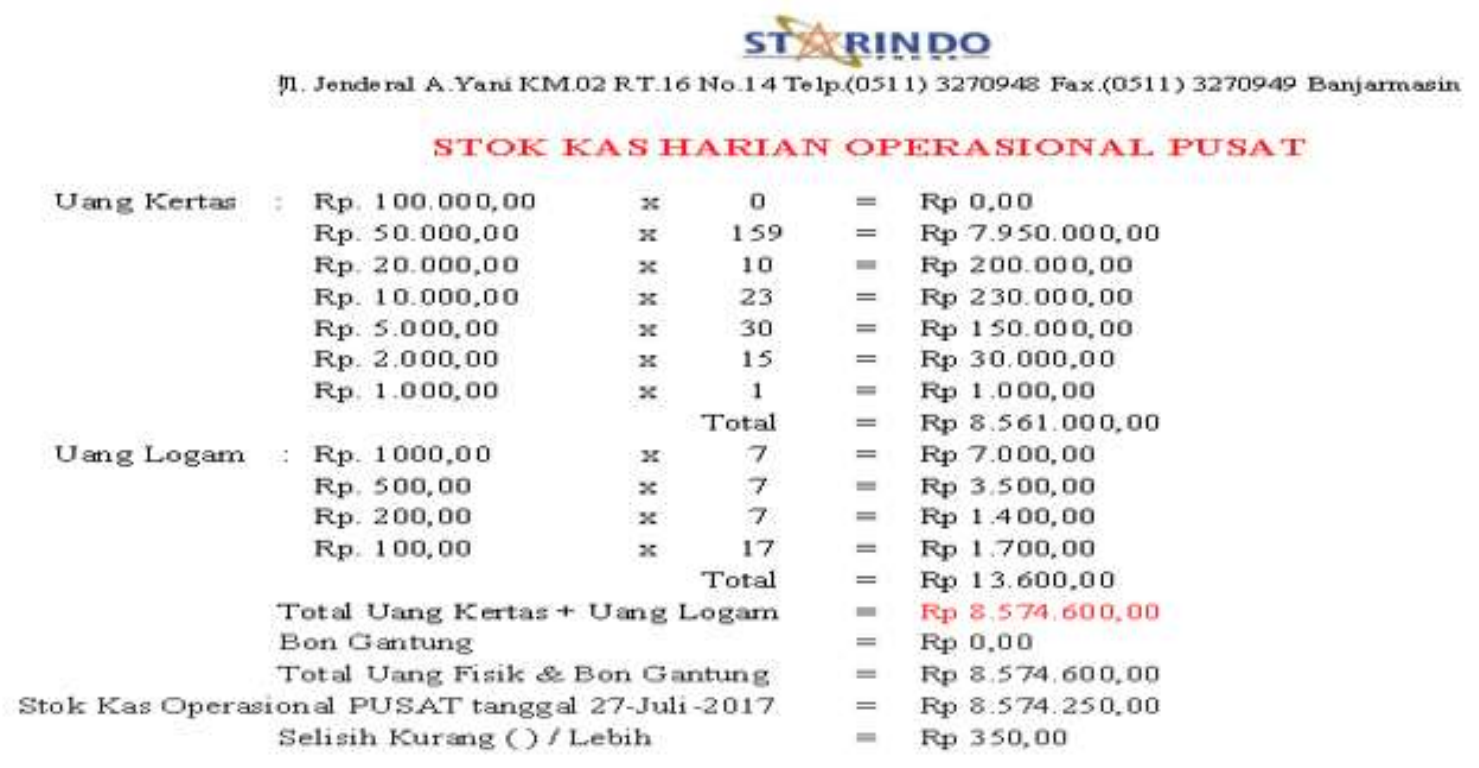

Gambar 9. Tampilan dari Laporan Stok Kas Harian

\section{KESIMPULAN}

\section{Kesimpulan}

Dengan adanya aplikasi pengelola data uang untuk kegiatan operasional ini, dapat ditarik suatu kesimpulan bahwa :

1. Proses pengolahan data uang yang digunakan untuk kegiatan operasional selama prosesnya berlangsung dapat dianalisa dan digunakan sebagai acuan untuk merancang dan membuat aplikasi ini.

2. Aplikasi yang dirancang dapat mengatasi kesulitan yang di hadapi, yakni manajer keuangan dapat memonitor langsung kondisi uang yang digunakan untuk kegiatan operasional, petugas kasir tidak lagi menggunakan fungsi copy dan paste saat akan membuat laporan atau pun bukti uang yang digunakan untuk kegiatan operasional, serta pengguna uang dapat melihat data uang yang ia gunakan, agar apabila terjadi kehilangan bukti uang yang ia terima, ia masih dapat melihat datanya melalui aplikasi.

3. Pembuatan laporan uang kegiatan operasional, bukti uang muka, bukti biaya, bukti kas masuk, bukti bon gantung, bukti stok kas, serta laporan biaya kegiatan operasional per jenis biaya menjadi mudah. Serta data uang yang digunakan untuk kegiatan operasional dapat disimpan di dalam database secara tersistem.

\section{DAFTAR PUSTAKA}

[1] Ardhana, Y. K. (2012). Dengan PHP : Membuat Website 30 Juta Rupiah. Bandung: Jasakom.

[2] Azhari, F. S. (2015, Maret 01). Analisis Dan Pembuatan Sistem Informasi Keuangan Berbasis Web Menggunakan Groovy Dan Grails Pada Esemka Mart Di Smk Abdi Negara Muntilan. Yogyakarta, Yogyakarta, Indonesia.

[3] Dwiartara, L. (2014). Menyelam \& Menaklukan Samudra PHP. Bogor: ilmuwebsite.com.

[4] Fadul, F. (2016, Februari 07). Apa Itu Bootstrap? Bagaimana Memulai Belajar Bootstrap Untuk Pemula. Diambil kembali dari dul.web.id: http://dul.web.id/bootstrap/3/tuts-tips/belajar-bootstrap-untukpemula.php

[5] Fata, H. A. (2007). Analisis dan Perancangan Sistem Informasi untuk Keunggulan Bersaing Perusahaan dan Organisasi Modern. Yogyakarta: Andi Publisher.

[6] Kadir, A. (2008). Dasar Pemrograman Web Dinamis Menggunakan PHP. Yogyakarta: ANDI Publisher.

[7] Kristanto, A. (2008). Perancangan Sistem Informasi dan Aplikasinya. Yogyakarta: Gava Media.

[8] Rusmayanti, A. (2014). Sistem Informasi Pengelolaan Keuangan Pada Desa Ngadirejan. Journal Speed - Sentra Penelitian Engineering dan Edukasi, 35-39.

[9] Setiawan, O. (2008). Panduan Membuat Data Flow Diagram, Entity Relationship Diagram, dan Database Menggunakan Power Designer. Bandung.

[10] Solichin, A. (2009, January 21). Achmatim.Net. Diambil kembali dari Achmatim.Net Tutorial Komputer dan Buku Pembelajaran Gratis: http://achmatim.net/2009/01/21/belajar-jquery-dari-buku-learningjquery/

[11] Sugiyono. (2016). Metode Penelitian Kuantitatif, Kualitatif, dan $R \& D$. Bandung: Alfabeta. 